\title{
Agricultural Residues as a Source of Bioactive Substances- Waste Management with the Idea of Circular Economy ${ }^{\dagger}$
}

\author{
Ewelina Gołębiewska *(D) and Monika Kalinowska *(D)
}

Citation: Gołębiewska, E.

Kalinowska, M. Agricultural

Residues as a Source of Bioactive

Substances-Waste Management with the Idea of Circular Economy.

Environ. Sci. Proc. 2021, 9, 2.

https://doi.org/10.3390/

environsciproc2021009002

Academic Editors: Dorota Anna Krawczyk, Iwona Skoczko and Antonio Rodero Serrano

Published: 29 September 2021

Publisher's Note: MDPI stays neutral with regard to jurisdictional claims in published maps and institutional affiliations.

Copyright: (C) 2021 by the authors Licensee MDPI, Basel, Switzerland. This article is an open access article distributed under the terms and conditions of the Creative Commons Attribution (CC BY) license (https:/ / creativecommons.org/licenses/by/ $4.0 /)$.
Department of Chemistry, Biology and Biotechnology, Institute of Civil Engineering and Energetics, Faculty of Civil Engineering and Environmental Science, Bialystok University of Technology, Wiejska 45E Street, 15-351 Bialystok, Poland

* Correspondence: e.golebiewska@pb.edu.pl (E.G.); m.kalinowska@pb.edu.pl (M.K.)

+ Presented at the Innovations-Sustainability-Modernity-Openness Conference (ISMO'21), Bialystok, Poland, 14 May 2021.

Abstract: Every year, the juice industry generates millions of tons of by-products worldwide such as seeds, skins and pomace. This creates significant environmental problems. It is estimated that about $25 \%$ of the fruit weight used in juice production is waste. However, even after processing, this waste contains high amounts of valuable bioactive substances. Phenolic compounds and pectin have been found to be the main components of apple pomace and are responsible for its antioxidant, antiinflammatory, antibacterial, antifungal, and anticancer properties. However, the low bioavailability and sensitivity of some chemicals limit their use in many areas. Advanced extraction techniques and encapsulation of apple pomace extracts is a promising technique to overcome these problems and increasing their applicability (e.g., in the cosmetic, pharmaceutical, or food industries).

Keywords: waste management; circular economy; by-products; apple pomace; bioactive compounds; polyphenols; nanoparticles

\section{Introduction}

Effective waste management is one of the greatest environmental challenges facing the world today. Food and green waste comprise the largest portion of waste, accounting for about $44 \%$ of the total global waste generation [1]. Among them, large groups are by-products from the fruit industries, such as apple pomace. Nowadays, apple pomace is mostly used as a substrate for production of bioethanol, pectin, organic fertilizer added to soil, and the production of animal feed [2]. However, not everyone is aware of the fact that even after processing, apple pomace still contains large amounts of valuable bioactive chemicals (e.g., phenolic compounds, dietary fiber, vitamins) [3]. Numerous studies have demonstrated that apple polyphenols exhibit anticancer, cardioprotective, and anti-diabetic properties [4]. Moreover, regular consumption of apples may prevent neurodegenerative diseases [5] and reduce asthma risk [6]. For these reasons, apples pomace should not be treated as a waste, but as a natural renewable source of valuable biocompounds that must be properly recovered. Classical extraction is one of the basic techniques used to isolate phytochemicals from plant material. In recent years, great importance has been attached to the search of extraction methods that will be efficient and at the same time environmentally friendly (e.g., by limiting the reducing the amounts of solvent used) [7]. However, some factors, such as the characteristic astringent and bitter taste or low bioavailability of the isolated compounds often limit their use in many fields. Numerous data from the literature indicate that encapsulation appears to be an appropriate technique to overcome these problems and therefore may increase their commercial applications [8].

In this short review, we will present the scale of apple and apple pomace production in Poland and in the world, green extraction techniques currently used to isolation bioactive compounds from fruit by-products, the synthesis of nanoparticles containing phenolic 
compounds isolated from apple pomace extract, and their potentially applications in food, pharmaceutical and cosmetic industries.

\section{Apple and Apple Pomace Production in Poland and World}

Statistics shows that in 2019, apples (after bananas and watermelons) were the third most popular fresh fruit in the world. In that year, 87.24 million metric tons of apples were produced worldwide [9]. In 2010-2018, annual apple production in Poland ranged from 1.877 to 3.9 million of tons [10]. It is estimated that about $50 \%$ of apples produced in Poland are processed for the production of apple juice concentrate [11]. Literature data show that $25-30 \%$ of the weight of the fresh apples used in the production of juice is fruit by-product called apple pomace, which represents a large amount of waste [12]. Based on these facts, it can be calculated that probably about 500,000 tons of apple pomace were generated in Poland in 2018. For comparison, a neighboring country (Germany) produces half as much apple pomace $(250,000$ tons per year) [13].

\section{Green Extraction Techniques}

Green extraction techniques are methods of separating bioactive compounds from plant material in an environmentally friendly manner. They rely on the use of alternative eco-friendly solvents, reducing the amount of chemicals, energy costs, and waste generation to obtain high quality extracts [14]. Supercritical fluid extraction (SFE), pressurized hot water extraction (PHWE), miniaturized solid phase extraction (MSPE), ultrasound-assisted (UAE), or a combination of assisted extraction techniques are becoming more and more popular. The SFE is a relatively new extraction method that uses liquids (most often $\mathrm{CO}_{2}$ ) which after pressuring and heating reach a supercritical state [15]. A similar technique is PHWE. However, in this case, water is used as a solvent. By increasing the temperature and pressure, water can obtain similar properties to ethanol, which causes an increase in the water solubility of many medium-polar compounds and an increase in extraction efficiency [16]. The MSPE is based on adsorption and desorption processes. First, the target analytes are captured and adsorbed on the sorbent surface, and then under the influence of high temperature they are desorbed (removed from the sorbent) [17]. The UAE generates high frequency pulses that increase the mass transfer of the extracted compounds to the solvent. This technique is often combined with other extraction methods (e.g., with Soxhlet extraction) [18].

\section{Synthesis and Applications of Nanoparticles}

Nanoencapsulation of bioactive compounds isolated from plants can increase their bioavailability, solubility, protection against environmental conditions (light, oxygen, moisture etc.) as well as degradation, and can control the release of ingredients in the organism and change the taste of the product [19]. In addition, the improvement of bioavailability and solubility of phytochemicals affects their absorption by the digestive system and skin [20]. These facts show that encapsulation techniques are promising methods for the production of functional food, drugs, and cosmetics. In nanotechnology various carriers such as liposomes, micelles, chitosan, and cyclodextrins are used [21]. Liposomes are carriers composed of phospholipid layer (one or more) and aqueous core with hydrophilic substances dissolved in it [22]. Due to their high affinity to biological cell membranes and ability to transport substances (encapsulation), liposomes easily penetrate the skin or are absorbed through both the oral mucosal lining and through the intestinal wall, wherein they then release the material contained therein [23]. The most popular techniques used for the preparation of nanoliposomes containing bioactive compounds are extrusion, sonification, and microfluidization [24]. The number of reports in the literature regarding the production and use of new liposomal nanoparticles is constantly increasing. In study of Savaghebi et al. algal extract-loaded nanoliposomes demonstrated improvement stability during storage and better oxidative stability than extracts alone. Moreover, the in vitro studies showed that synthesized nanoliposomes had a well-controlled release of polyphe- 
nols [25]. Another study found that adding nanoliposomes containing olive leaf extract (rich in phenolic compounds and oleuropein) to yoghurt improved the antioxidant activity and nutritional value of the product without changing the flavor and color [26]. Rafiee et al. demonstrated the potential of liposomal nanocarriers containing pistachio green hull extract as a bio-preservative to increase the antioxidant and antimicrobial properties of mayonnaise (extending the safe storage time) [27]. Nanoliposomes are also good anticancer agents [28].

\section{Conclusions}

Every year, the fruit processing industry generates huge amounts of fruit by-products, such as apple pomace, which contain significant quantities of bioactive compounds. In line with the idea of a circular economy, apple pomace should be reused responsibly. The use of green extraction techniques allows for the isolation of bioactive substances (including phenolic compounds) from apple pomace in an environmentally friendly manner, (i.e., by avoiding the use of toxic solvents and lower consumption of energy). Encapsulated polyphenols often exhibit improved shelf-stability, bioavailability, bioactivity, and solubility, making nanoparticles an interesting material for many applications in the food, cosmetic or pharmaceutical industries.

Author Contributions: M.K. conceptualization and editing; E.G. wrote the paper. Both authors have read and agreed to the published version of the manuscript.

Institutional Review Board Statement: Not applicable.

Informed Consent Statement: Not applicable.

Acknowledgments: The source of funding of the study was the fund Polish Ministry of Higher Education and Science nr WI/WB-IIŚ/3/2021.

Conflicts of Interest: The authors declare no conflict of interest.

\section{References}

1. Kaza, S.; Yao, L.C.; Bhada-Tata, P.; Van Woerden, F. What a Waste 2.0: A Global Snapshot of Solid Waste Management to 2050; World Bank: Washington, DC, USA, 2018.

2. Magyar, M.; da Costa Sousa, L.; Jin, M.; Sarks, C.; Balan, V. Conversion of apple pomace waste to ethanol at industrial relevant conditions. Appl. Microbiol. Biotechnol. 2016, 100, 7349-7358. [CrossRef]

3. Skinner, R.C.; Gigliotti, J.C.; Ku, K.M.; Tou, J.C. A comprehensive analysis of the composition, health benefits, and safety of apple pomace. Nutr. Rev. 2018, 76, 893-909. [CrossRef]

4. Kalinowska, M.; Gryko, K.; Wróblewska, A.M.; Jabłońska-Trypuć, A.; Karpowicz, D. Phenolic content, chemical composition and anti-/pro-oxidant activity of Gold Milenium and Papierowka apple peel extracts. Sci. Rep. 2020, 10, 14951. [CrossRef]

5. Kukull, W.A. An apple a day to prevent Parkinson disease: Reduction of risk by flavonoids. Neurology 2012, $78,1112-1113$. [CrossRef]

6. Shaheen, S.O.; Sterne, J.A.C.; Thompson, R.L.; Songhurst, C.E.; Margetts, B.M.; Burney, P.G.J. Dietary antioxidants and asthma in adults: Population-based case-control study. Am. J. Respir. Crit. Care Med. 2001, 164, 1823-1828. [CrossRef]

7. Płotka-Wasylka, J.; Rutkowska, M.; Owczarek, K.; Tobiszewski, M.; Namieśnik, J. Extraction with environmentally friendly solvents. TrAC Trends Anal. Chem. 2017, 91, 12-25. [CrossRef]

8. Munin, A.; Edwards-Lévy, F. Encapsulation of natural polyphenolic compounds; a review. Pharmaceutics 2011, 3, 793-829. [CrossRef]

9. Statista: Global Fruit Production in 2019, by Selected Variety. Statista. Available online: https://www.statista.com/statistics/26 4001/worldwide-production-of-fruit-by-variety / (accessed on 20 March 2021).

10. Rozkrut, D. (Ed.) Statistical Yearbook of Agriculture 2019; Zakład Wydawnictw Statystycznych: Warsaw, Poland, 2020.

11. PKO Bank Polski. Available online: https://www.pkobp.pl/centrum-analiz/analizy-sektorowe/ (accessed on 24 March 2021).

12. Bhushan, S.; Kalia, K.; Sharma, M.; Singh, B.; Ahuja, P.S. Processing of apple pomace for bioactive molecules. Crit. Rev. Biotechnol. 2008, 28, 285-296. [CrossRef]

13. Vukušić, J.L.; Millenautzki, T.; Cieplik, R.; Obst, V.; Saaid, A.M.; Clavijo, L.; Zlatanovic, S.; Hof, J.; Mösche, M.; Barbe, S. Reshaping Apple Juice Production Into a Zero Discharge Biorefinery Process. Waste Biomass Valorization 2020, 1, 1-11. [CrossRef]

14. Chemat, F.; Vian, M.A.; Cravotto, G. Green extraction of natural products: Concept and principles. Int. J. Mol. Sci. 2012, 13, 8615-8627. [CrossRef] 
15. Saini, A.; Panesar, P.S.; Bera, M.B. Valorization of fruits and vegetables waste through green extraction of bioactive compounds and their nanoemulsions-based delivery system. Bioresour. Bioprocess. 2019, 6, 26. [CrossRef]

16. Wong, V.; Wyllie, S.G.; Cornwell, C.P.; Tronson, D. Supercritical fluid extraction (SFE) of monoterpenes from the leaves of Melaleuca alternifolia (Tea Tree). Molecules 2001, 6, 92-103. [CrossRef]

17. Plaza, M.; Turner, C. Pressurized hot water extraction of bioactives. TrAC Trends Anal. Chem. 2015, 71, 39-54. [CrossRef]

18. Płotka-Wasylka, J.; Szczepańska, N.; de la Guardia, M.; Namieśnik, J. Miniaturized solid-phase extraction techniques. TrAC Trends Anal. Chem. 2015, 73, 19-38. [CrossRef]

19. Chemat, F.; Rombaut, N.; Sicaire, A.G.; Meullemiestre, A.; Fabiano-Tixier, A.S.; Abert-Vian, M. Ultrasound assisted extraction of food and natural products. Mechanisms, techniques, combinations, protocols and applications. A review. Ultrason. Sonochem. 2017, 34, 540-560. [CrossRef]

20. Nair, H.B.; Sung, B.; Yadav, V.R.; Kannappan, R.; Chaturvedi, M.M.; Aggarwal, B.B. Delivery of antiinflammatory nutraceuticals by nanoparticles for the prevention and treatment of cancer. Biochem. Pharmacol. 2010, 80, 1833-1843. [CrossRef]

21. Zhang, J.; Ma, P.X. Cyclodextrin-based supramolecular systems for drug delivery: Recent progress and future perspective. Adv. Drug Deliv. Rev. 2013, 65, 1215-1233. [CrossRef]

22. Sengel-Turk, C.T.; Gumustas, M.; Uslu, B.; Ozkan, S.A. Nanosized Drug Carriers for Oral Delivery of Anticancer Compounds and the Importance of the Chromatographic Techniques. In Nano- and Microscale Drug Delivery Systems: Design and Fabrication; Elsevier: Amsterdam, The Netherlands, 2017; pp. 165-195, ISBN 9780323527279.

23. Plaza-Oliver, M.; Santander-Ortega, M.J.; Lozano, M.V. Current approaches in lipid-based nanocarriers for oral drug delivery. Drug Deliv. Transl. Res. 2021, 11, 471-497. [CrossRef]

24. Mozafari, M.R. Nanoliposomes: Preparation and analysis. Methods Mol. Biol. 2010, 605, 29-50. [CrossRef]

25. Savaghebi, D.; Barzegar, M.; Mozafari, M.R. Manufacturing of nanoliposomal extract from Sargassum boveanum algae and investigating its release behavior and antioxidant activity. Food Sci. Nutr. 2020, 8, 299-310. [CrossRef]

26. Tavakoli, H.; Hosseini, O.; Jafari, S.M.; Katouzian, I. Evaluation of Physicochemical and Antioxidant Properties of Yogurt Enriched by Olive Leaf Phenolics within Nanoliposomes. J. Agric. Food Chem. 2018, 66, 9231-9240. [CrossRef] [PubMed]

27. Rafiee, Z.; Barzegar, M.; Sahari, M.A.; Maherani, B. Nanoliposomes Containing Pistachio Green Hull's Phenolic Compounds as Natural Bio-Preservatives for Mayonnaise. Eur. J. Lipid Sci. Technol. 2018, 120, 1800086. [CrossRef]

28. Karimi, N.; Bohlooli, S.; Mazani, M. Nanoliposomal formulation of Ecballium elaterium Extract: Cytotoxic evaluation against human gastric adenocarcinoma (AGS) cell line. Nanomed. Res. J. 2016, 1, 9-14. [CrossRef] 